\title{
O MERCOSUL E AS POLÍTICAS EDUCACIONAIS: UM BALANÇO DA ATUAÇÃO DO SETOR EDUCACIONAL DO MERCOSUL E DE SEUS PLANOS PARA A EDUCAÇÃO' ${ }^{1}$
}

\author{
THE MERCOSUR AND EDUCATIONAL POLICIES: A REVIEW OF THE \\ PERFORMANCE OF THE MERCOSUR EDUCATIONAL SECTOR AND ITS \\ PLANS FOR EDUCATION
}

DOI: $10.5380 / \operatorname{cg} . v 10 i 3.81903$

Lara Ciardelli Faria ${ }^{2}$

Ricardo Luigi3

\begin{abstract}
Resumo
O presente artigo visa o estudo de caso de uma organização intergovernamental de abrangência regional, o Mercosul, fazendo um balanço da atuação e das políticas educacionais do Setor Educacional do Mercosul (SEM). As Organizações Intergovernamentais (OIGs) têm um papel crucial no sistema internacional, intermediando as relações entre os Estados, proporcionando formas de resolver disputas e conflitos de interesses, promovendo a cooperação internacional. As OIGs influenciam as políticas educacionais formuladas por/para os Estados, desempenhando um papel fundamental no processo de internacionalização das políticas educacionais, com capacidade de orientar e enfatizar as políticas a serem seguidas nos âmbitos global, regional e nacional. O Mercosul visava, inicialmente, mais o caráter econômico-comercial do que o aspecto social, motivo pelo qual o termo "educação" somente apareceu um ano após a constituição da organização. O SEM, criado ainda em 1991, passou a sugerir políticas educacionais e trazer recomendações que contemplassem ações educacionais para os seus membros. Percebe-se que, no decorrer dos seis planos de ação educacional elaborados pelo SEM, muitas propostas foram feitas, mas pouco foi efetivado, demonstrando limitações para integrar as políticas regionais para a educação. Portanto, o objetivo do trabalho é analisar as principais propostas do SEM para a educação e pontuar os principais empecilhos que dificultam a sua efetivação. Para a execução do trabalho será utilizada a análise documental e bibliográfica, dialogando com as principais referências sobre o assunto, no intuito de esclarecer como as organizações internacionais promovem políticas educacionais em âmbito regional, destacando as principais questões referentes ao caso do Mercosul. Como resultado, verificou-se a baixa influência do SEM nas políticas educacionais nacionais.
\end{abstract}

Palavras-Chave: Mercosul; Setor Educacional do Mercosul (SEM)/ (Mercosul Educacional); Políticas Educacionais; Organizações Internacionais; Integração Regional.

\begin{abstract}
This article aims to do a case study of an intergovernmental organization with regional coverage, Mercosur, by making a review of the performance and educational policies of the Educational Sector of Mercosur (ESM). Intergovernmental Organizations (IOs) play a crucial role in the international system, mediating relations between States, providing ways to resolve disputes and conflicts of interest, promoting international

\footnotetext{
${ }^{1}$ Este artigo está licenciado sob a Licença Creative Commons Attribution (CC BY 4.0), sendo permitido o compartilhamento com reconhecimento da autoria e publicação inicial nesta revista.

${ }^{2}$ Graduanda em Geografia pela Universidade Federal Fluminense (UFF). E-mail: ciardellilara@gmail.com. ORCID: https://orcid.org/0000-0002-0773-1725.

3 Doutorado em Geografia pela Universidade Estadual de Campinas e Professor do Programa de Pósgraduação em Geografia (PPG) da Universidade Federal Fluminense. E-mail: ricardoluigi@id.uff.br. ORCID https://orcid.org/0000-0002-6634-2471.
} 
cooperation. IOs influence educational policies formulated by/for States, playing a fundamental role in the process of internationalization of educational policies, with the capacity to guide and emphasize policies to be followed at the global, regional and national levels. Mercosur initially aimed at the economic-commercial character rather than the social aspect, which is why the term "education" only appeared a year after the organization's constitution. The ESM, created in 1991, started to suggest educational policies and make recommendations that contemplated educational actions for its members. It is noticed that, during the six educational action plans elaborated by the ESM, many proposals were made, but little was carried out, which demonstrated limitations to integrate the regional policies for education. Therefore, the objective of this article is to analyze the main proposals of the ESM for education and point out the main obstacles that hinder its implementation. Documental and bibliographic analysis will be used to carry out this work, dialoguing with the main references on the subject, in order to clarify how international organizations promote educational policies at the regional level, highlighting the main issues related to the Mercosur case. As a result, it was verified the low influence of the ESM on national educational policies.

Keywords: Mercosur; Educational Sector of Mercosur (ESM) (Educational Mercosur); Educational Policies; International Organizations; Regional Integration.

\section{INTRODUÇÃO}

O Mercosul é uma organização internacional intergovernamental criada por meio do Tratado de Assunção, assinado em 1991, e composta, inicialmente, por Argentina, Brasil, Paraguai e Uruguai. A Venezuela ingressou no bloco em 2012, mas está suspensa desde 2016, e tanto seu ingresso no bloco quanto sua suspensão contam parte da história da organização. Originado em um contexto de euforia do processo de globalização nos anos 1990, com difusão dos princípios neoliberais e com ênfase na diminuição do papel do Estado, o Mercosul entrou em vigor com uma baixa institucionalização e privilegiando, inicialmente, aspectos econômicos e comerciais.

As discussões sobre educação, que não apareciam em seu documento fundador, foram inseridas no Mercosul um ano após a assinatura de seu tratado constitutivo (MERCOSUL, 2021). A partir do final de 1991, com a criação do Setor Educacional do Mercosul (SEM) ou Mercosul Educacional, após uma reunião de cúpula de ministros da Educação dos países membros, já se começou a pensar em políticas educacionais e recomendações que contemplassem ações educacionais para o conjunto. Essa proposta trouxe novas possibilidades de centralizar objetivos e metas comuns para a região, com um caráter inédito de orientar e coordenar políticas macroeconômicas e setoriais a serem efetivadas na educação.

A mudança de visão do Mercosul sobre o papel da educação se consolidou em seu período pós-hegemônico/ pós-liberal, iniciado em 2003, com a chamada “onda vermelha”, que foi a ascensão de lideranças políticas de esquerda (chamadas de progressistas) na América do Sul, alterando a forma de ver a integração regional, para além do aspecto comercial, ampliando a pauta sociopolítica.

O Mercosul, ao passar a enxergar a educação como um aspecto promotor de desenvolvimento, passa a articular seu setor educacional buscando aproximar ainda mais os países 
membros. Essa visão, entretanto, nestes 30 anos do Mercosul Educacional, parece que não há um grande avanço na incorporação desses planos educacionais por parte dos Estados membros.

A análise dos planos educacionais do Setor Educacional do Mercosul aqui posta busca contribuir para se traçar um panorama da trajetória do Mercosul Educacional. Os três primeiros planos demonstraram uma evolução que não se demonstrou nos planos seguintes, acompanhando as ondas de maior ou menor aprofundamento que acometem de forma cíclica a integração regional na América do Sul.

O objetivo deste artigo é analisar as mudanças no processo de integração promovido pelo Mercosul, com ênfase nas propostas do SEM para a educação, expressas em seus planos educacionais, pontuando os principais empecilhos que dificultaram a sua efetivação. Para a execução deste trabalho foi utilizada a análise documental e bibliográfica, buscando compreender como as organizações internacionais promovem políticas educacionais em âmbito regional, promovendo diálogos entre a abordagem regional da Geografia e as teorias das Relações Internacionais, sob a ótica, principalmente, do neofuncionalismo e do intergovernamentalismo.

A primeira seção do artigo, "O Mercosul e sua atuação na Educação: o Setor Educacional do Mercosul”, visou apresentar o Mercosul, no contexto de sua criação, apontando também o ambiente em que o Setor Educacional do Mercosul foi criado. Já na segunda seção, "O Setor Educacional do Mercosul e sua influência nas políticas educacionais", analisaram-se os planos educacionais do Mercosul, com vistas a analisar sua influência nas políticas educacionais dos Estados membros.

Como resultado dessa pesquisa, verificou-se uma baixa influência do SEM nas políticas educacionais nacionais. O Mercosul, em 2021, completando seus 30 anos de existência, encontra-se em nova turbulência, havendo discussões não só sobre a sua efetividade, como também questionamentos sobre a sua continuidade. A postura do governo brasileiro de Bolsonaro, com a saída do Brasil do Mercosul Educacional, em 2019, trouxe ainda mais problemas para a concretização das propostas educacionais da organização, culminando, inclusive, na falta de um plano para o quinquênio que se inicia em 2021.

\section{O MERCOSUl E SUA ATUAÇÃo NA EDUCAÇÃO: O SETOR EDUCACIONAL DO MERCOSUL}

O Mercosul é uma organização internacional do tipo intergovernamental. As Organizações Intergovernamentais são compreendidas por Herz, Hoffmann e Tabak (2015) e Luigi (2017) como instituições que atuam como mecanismo de estabilização da anarquia no sistema internacional, garantindo assim um funcionamento da governança global, em uma relação complexa e paradoxal, podendo gerar espaços sociais e físicos, para realizar negociações de pequena, média ou longa duração. Desta forma: 
No âmbito das organizações, está em curso um processo social complexo e que normas são criadas. Conhecimento é formado, e tarefas que cabem à comunidade internacional são tais como gerar desenvolvimento. Surgem novas categorias, como refugiados; difundem-se modelos de organização social e política, como a democracia liberal; e os próprios Estados podem redefinir seus interesses a partir dessa interação. (HERZ, HOFFMANN e TABAK, 2015, p.7).

Além da criação de normas e regras, as OIGs fornecem mecanismos para garantir o consentimento das mesmas, podendo, em certas circunstâncias, coagir atores a respeitar normas e regras por meio de pressão política e imposição de sanções ou até o uso de força militar.

As organizações intergovernamentais, podem influenciar tanto no âmbito de uma governança global, em que as ações dos Estados Nacionais dividem força com a atuação global e regional de outros atores políticos, como em âmbito regional supranacional, isso se dá por meio da integração regional.

A integração regional é compreendida por Luigi (2017) como uma forma de cooperação mais profunda entre os Estados, baseada em um regionalismo, definido como o princípio que norteia a integração regional e que deve ser qualificado, de forma a se conhecer a motivação por trás dos processos de regionalização. Embora seja objeto de ampla discussão conceitual, acabou sendo compreendida, de forma geral, sob seu cunho liberal, como "um instrumento para agregar forças e coordenar posições frente às negociações internacionais" (HERZ; HOFFMAN; TABAK, 2015, p. 168). Na definição de Haas (1958) ao tratar do processo de integração europeu, a integração regional é o processo pelo qual os atores políticos são persuadidos a transferir suas atitudes políticas para uma nova comunidade:

A integração política é o processo pelo qual os atores políticos em vários cenários nacionais distintos são persuadidos a mudar suas lealdades, expectativas e atividades políticas para um novo centro, cujas instituições possuem ou exigem jurisdição sobre os estados nacionais pré-existentes (HAAS, 1958, p. 16, tradução nossa).

Moravcsik (1993), com sua teoria intergovernamentalista, retoma parte das discussões de Haas (1958) ao rever o papel das instituições supranacionais na teoria neofuncionalista, situando a limitação da soberania das instituições como consequente da vontade dos líderes nacionais.

Nota-se que, com a ampliação global do espaço geográfico, com efeitos ainda mais propagados com a globalização, difundiram-se os processos de regulação na constituição das diversas regiões do mundo, estimulando os mecanismos de integração regional, que, com base nas organizações intergovernamentais, são considerados essenciais para o desenvolvimento econômico, social e cultural dos Estados. Nesta perspectiva se insere o Mercosul.

O Mercosul é um tipo especial de organização internacional, por ser uma organização intergovernamental, de propósito regional abrangente, voltada para a integração regional. Foi constituído em 1991, por intermédio do Tratado de Assunção, inicialmente sendo composto por 
Argentina, Brasil, Paraguai e Uruguai - a Venezuela ingressou em 2012, mas está suspensa desde 2016. O Protocolo de Ouro Preto, de 1994, foi um marco importante ao dar maior efetividade ao organismo, tornando-o sujeito de direito internacional e propiciando a sua institucionalização. Como definido por Junior e Santos (2017):

O Mercado Comum do Sul (MERCOSUL) é uma iniciativa dos anos 1990, ainda fortemente associada ao conceito de regionalismo aberto. Contudo, (...) houve muitas mudanças, particularmente com relação ao aprofundamento de algumas pautas para além daquelas tradicionalmente discutidas na região. Ficou claro que a busca do desenvolvimento regional iria além da (antiga) métrica que visava a garantir o crescimento econômico. Portanto, seria necessário investigar e investir na educação, dado seu potencial de contribuição para a transformação, seus impactos no médio/longo prazo, bem como o fato de ser considerada um direito humano e um bem público, possibilitando ainda o fomento à identidade regional. (JUNIOR E SANTOS, 2017, p. 23).

A organização privilegiou na sua criação um aspecto majoritariamente comercial da integração regional, mas, ao longo de sua trajetória, foi ampliando seu escopo:

Embora o bloco tenha nascido como quase exclusivamente comercial, como pode ser visto nas disposições do Tratado de Assunção, durante sua década inicial de existência conseguiu desenvolver uma forte dimensão trabalhista e educacional (...) (BRICEÑO-RUIZ, 2021, p. 68-69).

Apesar do termo "educação" não aparecer no tratado de criação do Mercosul, pouco depois da assinatura de seu tratado constitutivo já se começou a pensar em políticas educacionais e recomendações que contemplassem ações educacionais em conjunto para os países do bloco. A educação aparece em consonância com esses modelos teóricos de desenvolvimento, propostos em debates e encontros com outras organizações internacionais e outros ministros da educação.

Dessa forma, a educação se configura como um significativo elemento promotor do desenvolvimento em conjunto dos estados que constituem um bloco regional e assume um papel estratégico como fator produtivo de avanço econômico, social, político, cultural e humano. (SOUZA, 2017, p. 135).

Barboza (2009) mostra que isso faz parte dos princípios de uma estratégia comum de desenvolvimento, gerando uma crença idealizada de que essas medidas definem um marco da modificação da realidade na América Latina:

Em face disto, as instâncias do Mercosul advogam que a promoção da integração contribui para que os governos do bloco, na elaboração e aplicação das diversas políticas macroeconômicas e setoriais, possam comungar esforços no sentido de promover o desenvolvimento regional articulados em objetivos comuns. (BARBOZA, 2009, p. 61). 
Nessa linha de pensamento, foi criado o Setor Educacional do Mercosul (SEM) ou Mercosul Educacional. O SEM foi gestado ainda no ano 1991, na Reunião de Ministros da Educação dos Estados Partes, tendo passado a vigorar em 1992, a partir de tal diretriz, propondo-se a estimular planos de ação educacional visando orientar a formulação de políticas educacionais para os membros do Mercosul. Essa proposta trouxe novas possibilidades de centralizar objetivos e metas comuns para a região, com um caráter inédito de orientar e coordenar políticas macroeconômicas e setoriais a serem efetivadas na educação, tentando superar qualquer medida ou acordo configurados anteriormente. Nas palavras da instituição:

A missão do Setor Educacional do MERCOSUL é conformar um espaço educacional comum, através da concertação de políticas que articulem a educação e o processo de integração do MERCOSUL, estimulando a mobilidade, o intercâmbio, e a formação de uma identidade e cidadania regional, visando alcançar uma educação de qualidade para todos, com atenção especial para os setores mais vulneráveis em um processo de desenvolvimento com justiça social e respeito pela diversidade cultural dos povos da região (MERCOSUL, 2021, s/p).

As propostas iniciais do Mercosul Educacional buscaram suprir as necessidades objetivas existentes nos países, ligadas à área educacional, investindo no reconhecimento e no conhecimento mútuo de suas sociedades, promovendo uma cooperação entre os países. Visto que:

Apesar de geograficamente próximos havia, e ainda há, certo desconhecimento por parte das sociedades sul-americanas em relação aos seus vizinhos e parceiros, dificultada pelas precárias condições infraestruturais regionais. Por muitos séculos o diálogo preponderante dos países sul-americanos foi com as potências europeias e com os Estados Unidos. (ROSEVICS, 2015, p. 57).

Rosevics (2015) compreende que, para além das limitações do Mercosul no tocante à harmonização de interesses e concertação política, existe um outro fato preponderante para limitar as ações do SEM, ao menos durante a década de 1990:

o principal fator que limitou o Mercosul Educacional durante a década de 1990 foi a visão neoliberal conservadora de como processar a integração educacional no bloco. O foco na integração das estruturas educacionais dos países da região, ainda que relevante, engessou as possibilidades criativas e transformadoras do órgão para com o bloco e os povos da região na década de 1990. (ROSEVICS, 2015, p. 57).

A integração regional é considerada uma palavra-chave para o desenvolvimento, e os planos formulados pelo Mercosul Educacional buscam defender as implementações de medidas para a aprimoração das políticas educacionais, o que será verificado na próxima seção. 


\section{O SETOR EDUCACIONAL DO MERCOSUL E SUA INFLUÊNCIA NAS POLÍTICAS EDUCACIONAIS}

As OIGs desempenham um papel fundamental no processo de internacionalização das políticas educacionais segundo Akkari (02011), atuando na formulação de políticas educacionais por/para os Estados tanto no âmbito global quanto regional, partilhando forças de atuação com outros atores políticos, quanto em escala regional supranacional, promovida por meio da integração regional e, na escala nacional, por meios de políticas locais. O Mercosul, ao ampliar sua agenda para as questões sociais (BRICEÑO-RUIZ, 2021) avançou por sobre as questões educacionais.

Poucos meses após a assinatura de seu tratado constitutivo, os representantes do Mercosul já começaram a pensar em políticas educacionais e recomendações que contemplassem ações educacionais em conjunto para os países da organização. Assim, foi criado o Setor Educacional do Mercosul (SEM), ou Mercosul Educacional, propondo-se a estimular planos de ação educacional visando orientar a formulação de políticas educacionais para os membros do Mercosul.

Foram analisados os seis planos de ação educacional elaborados pelo SEM, desde 1992 até os dias atuais (BARBOZA, 2009; CEVIDANES, 2019; JUNIOR E SANTOS, 2017), sendo possível perceber, nos três primeiros planos, uma evolução que não se manteve nos planos seguintes.

O primeiro plano (1992-1994) não contava com nenhuma estrutura administrativa ou organizacional do SEM, tendo sido apresentado sem nenhuma meta ou ajuste nos níveis educacionais. Propagando o pensamento teórico por meio do programa chamado "formação da consciência cidadã favorável ao processo de integração" (MERCOSUL, 2000, p. 2), teve como finalidade "promover o conhecimento do impacto da integração e difundir esta informação nos diferentes níveis do sistema educativo e implementar o ensino do Espanhol e do Português em instituições dos diferentes níveis e modalidades do sistema educativo” (MERCOSUL, 200o, p. 2).

De maneira geral, Barboza (2009) aponta o primeiro plano como "apresentado de maneira sintética", porém com aspectos relevantes, como, por exemplo, a proposição da integração sociolinguística como parte essencial para o fortalecimento dessa integração regional, pois, sem uma política educacional voltada para o aprendizado das línguas dos países membros, o objetivo de fortalecer as relações comerciais para além das fronteiras poderia ser limitado pelos empecilhos idiomáticos.

O segundo plano (1998-2000) demonstrou aprofundamento das questões tratadas no primeiro, com maior sistematização das ideias e formulação de propostas e atividades práticas. $\mathrm{O}$ documento prioriza duas áreas, o desenvolvimento da identidade regional e a promoção de políticas regionais de capacitação de recursos humanos e de melhoria da qualidade da educação (MERCOSUL, 2020).

O terceiro plano (2001-2005) é pioneiro ao tratar com detalhes de medidas e ações para cada nível de ensino, abordando diretamente a educação básica, a educação tecnológica e a educação 
superior. Também neste plano ocorre a setorização da execução dos trabalhos do SEM, institucionalizando e criando instâncias burocráticas para o seu funcionamento, com os princípios conceituais que sustentariam as proposições para a educação no Mercosul. Ainda no terceiro plano, alterou-se a validade dos planos educacionais do Mercosul de três para cinco anos, permitindo aos governos dos países membros mais tempo para a execução, em âmbito nacional, das medidas acordadas para a política educacional.

O quarto plano (2006-2010), o quinto plano (2011-2015) e o sexto plano (2016-2020) foram pensados sob uma mesma estrutura, reforçando o que já vinha sendo apresentado desde o primeiro plano, na perspectiva de uma integração regional com propósito de ampliação funcional da educação enquanto política social.

Mais especificamente, o quarto plano trouxe como principal questão a necessidade de construir-se um fundo de financiamento no SEM, envolvendo as mais diversas origens, dos governos nacionais, de organizações internacionais governamentais e não governamentais e de atores privados, visando, principalmente, uma mudança mais profunda nas infraestruturas de ensino e uma maior qualificação docente.

O quinto plano trouxe poucas inovações, institucionalizando demandas que existiam desde o primeiro plano e reforçando a importância do estudo sobre as línguas dos países membros para reforçar o processo de integração regional. Um grande marco institucional promovido por esse plano foi a criação de metas para alcance dos objetivos propostos.

Por sua vez, o sexto plano trouxe como metas prioridades estruturadas em torno de quatro eixos: 1- geração e difusão de conhecimento, voltado para a difusão de informações entre os Estados membros; 2- mobilidade para a integração regional, voltado para a mobilidade entre instituições educacionais; 3- qualidade e equidade, abarcando a questão da qualidade educacional; 4- inclusão e participação social, que tem como foco ampliar a participação popular e promover maior atenção às necessidades socioeducativas. De acordo com Cevidanes (2019, p. 18), "O $6^{\circ}$ plano não propôs a criação de programas e comissões, tampouco de extinção daqueles criados anteriormente. Se dedicou apenas em expandir, institucionalizar e sistematizar os programas já existentes”.

Em geral, esses planos reafirmam a necessidade de formação e de especialização dos docentes de História e Geografia para incorporarem o estudo da região em seus programas. Além disso, trouxeram a obrigatoriedade do espanhol e do português como segunda língua nos países membros. Mostram-se ainda dispostos à inclusão e ao desenvolvimento, que viriam incorporados das novas tecnologias e do acesso a elas, contemplando a educação em espaços não formais, a educação à distância, modificando a visão de educação na região para um modelo mais amplo. O quadro 1 busca sistematizar as principais questões trazidas por cada um dos planos educacionais do Mercosul. 
QUADRO 1: OS PLANOS EDUCACIONAIS DO MERCOSUL

\begin{tabular}{|c|c|}
\hline $\begin{array}{c}1^{\circ} \text { plano } \\
(1992-1994)\end{array}$ & $\begin{array}{c}\text { Nenhuma estrutura administrativa ou organizacional do SEM; } \\
\text { Nenhuma meta ou ajustes nos níveis educacionais; } \\
\text { Integração sociolinguística. }\end{array}$ \\
\hline $\begin{array}{l}2^{\circ} \text { plano } \\
(1998-2000)\end{array}$ & $\begin{array}{l}\text { Duas áreas prioritárias: } \\
\text { Área I: Desenvolvimento da identidade regional por meio do estímulo do conhecimento } \\
\text { mútuo e de uma cultura de integração. } \\
\text { Área II: Promoção de políticas regionais de capacitação de recursos humanos e melhoria } \\
\text { da qualidade da educação. }\end{array}$ \\
\hline $\begin{array}{c}3^{\circ} \text { plano } \\
(2001-2005)\end{array}$ & $\begin{array}{l}\text { Expõe detalhes de medidas e ações para cada nível de ensino; } \\
\text { Setorização e execução dos trabalhos no SEM; } \\
\text { Criação do Comitê Coordenador Regional (CCR); } \\
\text { Criação do Sistema de Informação e comunicação (SIC); } \\
\text { Amplia a sua atuação de três a cinco anos; } \\
\text { Redefinição da missão, aspecto social atribuído à educação. }\end{array}$ \\
\hline $\begin{array}{c}4^{\circ} \text { plano } \\
(2006-2010)\end{array}$ & $\begin{array}{l}\text { Apresenta maior descrição, com fundamentos técnicos e metodológico; } \\
\text { Criação do Fundo de Financiamento do Setor Educacional do Mercosul (FEM); } \\
\text { Reforça motivos de mudanças nas políticas econômicas, orientações e prioridades; } \\
\text { Destaca novos objetivos para cada nível de ensino a ser seguido e mediado pelos } \\
\text { governos de cada Estado pertencentes ao Mercosul. }\end{array}$ \\
\hline $\begin{array}{c}5^{\circ} \text { plano } \\
(2011-2015)\end{array}$ & $\begin{array}{l}\text { Segue o mesmo nível de organização e detalhamentos dos planos anteriores; } \\
\text { Criação de Comissão Regional Coordenadora de Formação docente. (CRC FD). }\end{array}$ \\
\hline $\begin{array}{c}6^{\circ} \text { plano } \\
(2016-2020)\end{array}$ & $\begin{array}{l}\text { Foco nos seguintes aspectos: } \\
\text { geração e difusão de conhecimento; } \\
\text { mobilidade para a integração regional; } \\
\text { qualidade e equidade; } \\
\text { inclusão e participação social. }\end{array}$ \\
\hline
\end{tabular}

Fonte: os autores (2021).

O quadro 1 confirma o diagnóstico das principais referências, endossando a constatação de que as perspectivas de uma contribuição do Mercosul para as políticas regionais de educação pareceram, analisando o que foi feito até aqui, pouco promissoras:

No âmbito do MERCOSUL, como base nesses objetivos estratégicos e os demais documentos editados, observamos que os destaques vêm ao encontro daquilo já expresso pelos organismos internacionais, sobretudo no que diz respeito às potencialidades da educação para o desenvolvimento e a transformação social. 
Observa-se ainda que os referidos Planos de Educação se constituem mais como uma carta de orientações para os países membros de bloco do que, efetivamente, uma proposição para a construção de políticas públicas educacionais no âmbito doméstico e da região (JUNIOR; SANTOS, 2017, p. 12).

As políticas educacionais, além de não serem inovadoras, soaram mais como uma cartilha, parecendo não haver um grande avanço na incorporação desses planos por parte dos Estados membros.

Na mesma direção, apontou o então ministro da Educação do Brasil, Abraham Weintraub, afirmando que, em 28 anos da participação do Brasil na área educacional do Mercosul, não havia resultados concretos para mostrar (MEC, 2019). Sobre esse relato, Amaral e Serikawa (2020) lançaram uma nota dizendo que:

Em sua essência, o Setor não tem a pretensão de impactar diretamente sobre os indicadores de qualidade dos países. Não é essa sua finalidade. Sua função é ser um foro de diálogo e coordenação entre países com realidades e desafios educacionais historicamente semelhantes que permita a interação e a troca de experiências com a construção de propostas conjuntas que alimentem, inclusive, o processo de integração econômica. (AMARAL, SERIKAWA, 2020, s/p.).

Em substituição à mediação do Mercosul, o ministro afirma que propostas de medidas bilaterais possam ser mais efetivas. O ministro da educação, em novembro de 2019, argumentou também que “as reuniões bilaterais têm custos, mas 'têm começo, meio e fim e um objetivo claro'. (CLAVERY, 2019, p. 1)”. Nenhuma dessas afirmações foi comprovada com números, dados, ou qualquer forma de argumentação explicativa, mas acompanham um posicionamento político do atual governo do Brasil, também seguido pelo governo do Uruguai, empossado em 2020, de preferência por negociações bilaterais em detrimento do multilateralismo.

\section{CONSIDERAÇÕES FINAIS}

O Mercosul, pensando inicialmente como um mecanismo de integração regional voltado para o comércio, assumiu durante o seu desenvolvimento outras características, abrangendo também políticas sociais. Nesse contexto, surgiram as políticas educacionais do Mercosul, expostas pelos seis planos de ação do Setor Educacional do Mercosul, que se inserem em um quadro de integração regional com perspectivas de ampliação funcional da educação enquanto política social.

Os planos de ação do Mercosul educacional demonstram o potencial de contribuição para a transformação e o fomento à identidade regional. Entretanto, faz-se necessária uma investigação sobre o investimento da organização na educação e os seus impactos no médio/longo prazo. Notouse que os planos muitas vezes ficaram somente no papel e pouco se implementaram as ações propostas. Uma análise dos planos do Mercosul para a educação, seja pelo acompanhamento das 
discussões com base nos documentos propostos, seja pelo levantamento das principais referências bibliográficas trabalhadas, demonstra que pouco se avançou.

Um dos empecilhos encontrados na aplicação dos planos educacionais é que os próprios países partes não aproveitam as propostas para a construção de políticas públicas educacionais, nem para o âmbito doméstico nem para o âmbito regional, sendo na verdade essas políticas consideradas como uma carta de orientações para os países membros.

Preocupa que o último dos seis planos de ação educacional tenha se encerrado em 2020, e que o plano para coordenar as políticas educacionais do Mercosul, a partir de 2021, tenha começado a ser produzido no mês de agosto de 2021, contrariando a lógica de organização dos planos anteriores. A pretensa saída do Brasil do Mercosul Educacional, em 2019, foi revista em 2021, mas é um dos fatores que contribuiu para a desestruturação dos arranjos educacionais regionais com base no Mercosul.

A análise documental e bibliográfica não permitiu identificar a influência das propostas do Mercosul nos sistemas educacionais dos Estados partes, desta forma cabe aprofundar o exame das razões do porquê de as políticas regionais educacionais do Mercosul não terem alcançado o resultado esperado, com aparente baixa incorporação desses planos por parte dos Estados membros.

O Mercosul, em seu setor educacional, promove um modelo de integração regional que, para dar resultado, necessita da adoção de medidas mais amplas. No campo educacional é preciso aumentar a participação ativa dos Estados e manter seus compromissos, apesar das mudanças políticas que causam instabilidade nos compromissos políticos regionais.

*Artigo recebido em 13 de julho de 2021, aprovado em 03 de novembro de 2021.

\section{REFERÊNCIAS}

AMARAL, Joana de Barros; SERIKAWA, Leonardo. Em defesa do Mercosul Educacional. Disponível em: https://www.obs.org.br/integracao/1152-mercosuleducacional. Acesso em: 12 jul. 2021.

BARBOZA, Mário de Jesus. Política de educação nos planos do setor educacional do Mercosul: a educação como elemento de integração e desenvolvimento regional. Dissertação de Mestrado. Cascavel, PR: UNIOESTE, 2009.

BRICEÑO-RUIZ, José. O auge e a crise do "Novo Mercosul” no período pós-hegemônico (20032016). Lua Nova, São Paulo, 2021, 112, p. 55-82.

CEVIDANES, Kamila Nogueira. Conquistas e desafios da Educação nos Planos de ação do setor educacional do MERCOSUL. Artigo de conclusão de curso (História-licenciatura) Universidade Federal da Integração Latino-Americana (UNILA), Foz do Iguaçu, 2019. 
CLAVERY, Elisa. Brasil deixará grupo de trabalho sobre educação do Mercosul, diz ministro. TV Globo, Brasília, 29 nov. 2019. Disponível em: https://g1.globo.com/educacao/noticia/2019/11/29/brasil-deixara-grupo-de-trabalho-sobreeducacao-do-mercosul-diz-ministro.ghtml. Acesso em: 12 jul. 2021.

HAAS, Ernest. The Uniting of Europe: Political, Social and Economic Forces, 1950-1957. Stanford: Stanford University Press, 1958.

HERZ, Mônica; TABAK, Jana; HOFFMANN; Andrea Ribeiro. Organizações internacionais: história e práticas. 2. ed. Rio de Janeiro: Elsevier, 2015.

LUIGI, Ricardo. A integração regional na América do Sul: a efetividade da União das Nações Sul-Americanas (Unasul). Tese (Doutorado em Geografia), Instituto de Geociências da Universidade Estadual de Campinas (Unicamp), 2017. Disponível em: http://repositorio.unicamp.br/bitstream/REPOSIP/330751/1/LuigiJunior_RicardoAbrate_D.pdf. Acesso em: 12 jul. 2021.

LUIGI, Ricardo. Educação e a atuação das organizações internacionais frente à pandemia de COVID19. In: SENHORAS, Elói Martins. (Org.). COVID-19 e Educação: Debates entre o Global e o Local. Boa Vista: EdUFRR, 2020.

MEC. Educação brasileira sairá do Mercosul. Disponível em: http://portal.mec.gov.br/component/content/article?id=83131. Acesso em: 12 jul. 2021.

MERCOSUl. Página do Setor Educacional do Mercosul. Disponível em: https://www.mercosur.int/pt-br/temas/educacao/. Acesso em 12 jul. 2021.

MORAVCSIK, Andrew. Preferences and Power in the European Community: A Liberal Intergovernmentalist Approach. Journal of Common Market Studies, v.31, n.4, p. 473-524, 1993. Disponível em: http://citeseerx.ist.psu.edu/viewdoc/download;jsessionid=3B867BACoEoCo2518E86528AB8152 6DD?doi=10.1.1.463.7692\&rep=rep1\&type=pdf. Acesso em 01 nov. 2021.

ROSEVICS, Larissa. O Mercosul educacional e a criação da Unila no início do século XXI: integração regional via educação. Tese (Doutorado em Economia política internacional). Universidade Federal do Rio de Janeiro, 2015.

SANTOS, Thauan; DINIZ JÚNIOR, Carlos Antônio. Integração Regional e Educação: O caso do MERCOSUL. Oikos, Rio de Janeiro, 2017, v.16, n.2, p.22-36.

SOUZA, Kellcia Rezende. Direito à educação nos países membros do MERCOSUL: um estudo comparado. Tese (Doutorado em Educação Escolar). Universidade Estadual de São Paulo, 2017. 